\title{
Highlight report: towards the replacement of in vivo repeated dose systemic toxicity testing
}

\author{
Jan G. Hengstler $\cdot$ Rosemarie Marchan • \\ Marcel Leist
}

Published online: 21 December 2011

(C) Springer-Verlag 2011

Recently, the European Union, together with the European cosmetics industry represented by Colipa, initiated the "SEURAT-1" program to develop in vitro and in silico test systems with the goal to eventually replace in vivo repeated dose systemic toxicity testing. The results and concepts will be published in a series of six annual books, the first of which was recently released (Schwarz and Gocht 2011).

Repeated dose systemic toxicity testing has been a major topic frequently addressed in our journal (Bruchajzer et al. 2010; Heo et al. 2010; Pestka 2010; Tasaki et al. 2009; Kumar and Gill 2009). Of note, Rupp et al. (2010) have recently applied a computational QSAR tool to predict chronic oral LOAEL. In their study, they predicted LOAELS for 807 industrial chemicals and compared the predicted values to the experimental LOAELS. Due to the exclusion criteria of the QSAR tool, prediction was not possible for 460 compounds. Of the remaining 347 chemicals, 34-62\% were predicted within a range of $0.2-$ and fivefold compared to the experimentally obtained LOAELS. Their results illustrate the ambiguity of in silico chronic LOAEL prediction and the need for more refined prediction tools (Rupp et al. 2010).

The relevance of repeated dose testing is illustrated by numerous recently published studies, e.g., the role of chronic 4-n-nonylphenol or methylmercury exposure on aortic vasoconstriction and hypertension (Hsieh et al. 2009;

J. G. Hengstler $(\varangle) \cdot$ R. Marchan

Leibniz Institut für Arbeitsforschung an der TU Dortmund, Leibniz Research Centre for Working Environment and Human Factors (IfADo), Ardeystrasse 67, 44139 Dortmund, Germany e-mail: hengstler@ifado.de

M. Leist

Fachbereich Biologie, Universität Konstanz,

Universitätsstr. 10, 78457 Konstanz, Germany
Grotto et al. 2009), the relevance of chronic oxidative stress in alcohol-induced liver injury (Cederbaum et al. 2009), immunotoxicity by chronic exposure to perfluorooctanesulfonate (Dong et al. 2009), and renal dysfunction as a consequence of chronic exposure to depleted uranium (Zhu et al. 2009). It is also well established that induction or inhibition of detoxifying enzymes (Gebhardt et al. 2003; Hengstler et al. 2000; Hewitt et al. 2007) or protective factors (Ilowski et al. 2010, 2011) plays an important role in repeated dose toxicity. Moreover, much progress has been achieved in physiologically based toxicokinetic modelling to predict relevant concentrations for in vitro testing (Mielke et al. 2011). However, relatively little is known about the differences in mechanisms relevant for repeated dose and acute toxicity. Is repeated dose toxicity simply a consequence of the prolonged activity of the same toxic pathways that cause acute toxicity? An example of repeated dose hepatotoxicity can be used to illustrate that this is not necessarily the case:

\section{Liver fibrosis}

Single administration of high doses of $\mathrm{CCl}_{4}$ causes cell death to a fraction of hepatocytes located at the centre of the liver lobules, because only the central hepatocytes express the metabolically activating CYP2E1 (Hoehme et al. 2010; Bauer et al. 2009). In less than 10 days, the dead cell area completely regenerates. The regenerated liver is functionally and morphologically undistinguishable from control livers. However, if lower doses of $\mathrm{CCl}_{4}$ are administered over 6 weeks (two injections per week), liver fibrosis is observed. Interestingly, fibrosis occurs in the periphery of the liver lobules, and not at the centre where cell killing of hepatocytes takes place. This scenario is 
most probably explained by the release of cytokines by stressed or dying hepatocytes. These cytokines activate liver stellate cells to form myofibroblasts that secrete large amounts of extracellular matrix, finally leading to fibrosis and destruction of the liver architecture. Since (for unknown reasons) stellate cells and myofibroblasts prefer to localize to the periportal region, the pattern of $\mathrm{CCl}_{4^{-}}$ induced cell death (in the centre of liver lobules) does not correspond to the pattern of fibrosis (in the periphery of liver lobules). Although $\mathrm{CCl}_{4}$ is not clinically relevant, it represents the best studied model compound that is prototypical for other compounds causing pericentral liver damage, and for which metabolic activation by CYP2E1 is relevant. Clinically relevant examples include ethanol or paracetamol. In addition, liver fibrosis after bile duct ligation, mdr2 knockout (which leads to bile salt toxicity), viral hepatitis or alcohol abuse (Hengstler et al. 2009) all seem to be caused by a secondary mechanism where toxicity to hepatocytes activates stellate cells.

\section{Idiosyncratic drug-induced liver injury (DILI)}

One mechanism leading to DILI is that drugs are activated to reactive intermediates in hepatocytes and form protein adducts that may function as haptens. It may take several weeks to months and repeated doses over a longer period until immune cells have proliferated and matured sufficiently in order to induce a clinically evident DILI. Recently, evidence has been presented that even complex mechanisms requiring repeated doses and interaction of several cell types may be predicted by relatively simple in vitro systems: considering both, protein binding of compounds to liver proteins and the daily dose of drugs allows a good differentiation between DILI inducing and negative compounds (Usui et al. 2009; Nakayama et al. 2009). Using this approach, the positive DILI compounds acetaminophen, alpidem, bromfenac, carbamazepine, diclofenac, flutamide, imipramine, nefazodone, tacrine, ticlopidine, tienilic acid, and troglitazone could be differentiated from negative compounds acetylsalicylic acid, caffeine, dexamethasone, losartan, ibuprofen, paroxetine, pioglitazone, rosiglitazone, sertraline, theophylline, venlafaxine, and zolpidem (Usui et al. 2009).

\section{Steatosis and steatohepatitis}

Several drugs can induce steatosis, the accumulation of lipid droplets in hepatocytes. Examples are amiodarone that inhibits beta-oxidation, tamoxifen that increases triacylglycerol biosynthesis or fialuridine that compromises mitochondrial functions (review: Amacher 2011a, b). Also the activation of Kupffer cells, the tissue macrophages of the liver, may contribute to steatosis, since Kupffer cells secrete cytokines such as IL-1beta that suppress PPARalpha expression a control factor of several genes involved in transport and oxidation of free fatty acids (Amacher 2011a, b). Already the induction of a fully established steatosis may require repeated doses. Druginduced steatosis may progress to steatohepatitis, a serious condition of fibrosis or cirrhosis which may lead to liver failure. The "two hit theory" tries to explain pathogenesis of steatohepatitis (review: Amacher 2011a, b). The first hit is induced by repeated doses of a drug leading to steatosis. Next a "second hit" causes progression of usually asymptomatic steatosis to clinically evident steatohepatitis. Although the exact nature of the "second hit" is not fully understood, it is clear that steatosis, e.g., induced and maintained by repeated doses of drugs, clearly enhances the risk of steatohepatitis.

The above examples may be sufficient to illustrate that one compound may cause both acute and repeated dose toxicity by different pathways. However, research on the mechanisms of repeated dose toxicity is still at an early stage but promises an unusually dynamic and successful field of research. The book series by Schwarz and Gocht (which can be down loaded from the following website: http://www.seurat-1.eu/pages/library/seurat-1-annual-report. php) will be interesting for anyone interested in repeated dose systemic toxicity testing.

\section{References}

Amacher DE (2011a) Strategies for the early detection of druginduced hepatic steatosis in preclinical drug safety evaluation studies. Toxicology 279(1-3):10-18. Epub 2010 Oct 23. Review

Amacher DE (2011b) The mechanistic basis for the induction of hepatic steatosis by xenobiotics. Expert Opin Drug Metab Toxicol 7(8):949-965

Bauer A, Schumann A, Gilbert M, Wilhelm C, Hengstler JG, Schiller J, Fuchs B (2009) Evaluation of carbon tetrachloride-induced stress on rat hepatocytes by 31P NMR and MALDI-TOF mass spectrometry: lysophosphatidylcholine generation from unsaturated phosphatidylcholines. Chem Phys Lipids 159(1):21-29

Bruchajzer E, Frydrych B, Sporny S, Szymańska JA (2010) Toxicity of penta- and decabromodiphenyl ethers after repeated administration to rats: a comparative study. Arch Toxicol 84(4):287299

Cederbaum AI, Lu Y, Wu D (2009) Role of oxidative stress in alcohol-induced liver injury. Arch Toxicol 83(6):519-548

Dong GH, Zhang YH, Zheng L, Liu W, Jin YH, He QC (2009) Chronic effects of perfluorooctanesulfonate exposure on immunotoxicity in adult male C57BL/6 mice. Arch Toxicol 83(9): $805-815$

Gebhardt R, Hengstler JG, Müller D, Glöckner R, Buenning P, Laube B, Schmelzer E, Ullrich M, Utesch D, Hewitt N, Ringel M, Hilz BR, Bader A, Langsch A, Koose T, Burger HJ, Maas J, Oesch F (2003) New hepatocyte in vitro systems for drug metabolism: 
metabolic capacity and recommendations for application in basic research and drug development, standard operation procedures. Drug Metab Rev 35(2-3):145-213

Grotto D, de Castro MM, Barcelos GR, Garcia SC, Barbosa F Jr (2009) Low level and sub-chronic exposure to methylmercury induces hypertension in rats: nitric oxide depletion and oxidative damage as possible mechanisms. Arch Toxicol 83(7):653-662

Hengstler JG, Utesch D, Steinberg P, Platt KL, Diener B, Ringel M, Swales N, Fischer T, Biefang K, Gerl M, Böttger T, Oesch F (2000) Cryopreserved primary hepatocytes as a constantly available in vitro model for the evaluation of human and animal drug metabolism and enzyme induction. Drug Metab Rev 32(1):81-118

Hengstler JG, Godoy P, Stewart JD, Bolt HM (2009) Alcohol-induced liver injury: how a small molecule overwhelms one of the cell types with the best regeneration capacity of the human body. Arch Toxicol 83(6):513-514

Heo JD, Oh JH, Lee K, Kim CY, Song CW, Yoon S, Han JS, Yu IJ (2010) Gene expression profiling in the lung tissue of cynomolgus monkeys in response to repeated exposure to welding fumes. Arch Toxicol 84(3):191-203

Hewitt NJ, Lechon MJ, Houston JB, Hallifax D, Brown HS, Maurel P, Kenna JG, Gustavsson L, Lohmann C, Skonberg C, Guillouzo A, Tuschl G, Li AP, LeCluyse E, Groothuis GM, Hengstler JG (2007) Primary hepatocytes: current understanding of the regulation of metabolic enzymes and transporter proteins, and pharmaceutical practice for the use of hepatocytes in metabolism, enzyme induction, transporter, clearance, and hepatotoxicity studies. Drug Metab Rev 39:159-234

Hoehme S, Brulport M, Bauer A, Bedawy E, Schormann W, Hermes M, Puppe V, Gebhardt R, Zellmer S, Schwarz M, Bockamp E, Timmel T, Hengstler JG, Drasdo D (2010) Prediction and validation of cell alignment along microvessels as order principle to restore tissue architecture in liver regeneration. Proc Natl Acad Sci USA 107(23):10371-10376

Hsieh CY, Miaw CL, Hsieh CC, Tseng HC, Yang YH, Yen $\mathrm{CH}$ (2009) Effects of chronic 4-n-nonylphenol treatment on aortic vasoconstriction and vasorelaxation in rats. Arch Toxicol 83(10): 941-946

Ilowski M, Putz C, Weiss TS, Brand S, Jauch KW, Hengstler JG, Thasler WE (2010) Augmenter of liver regeneration causes different kinetics of ERK1/2 and Akt/PKB phosphorylation than EGF and induces hepatocyte proliferation in an EGF receptor independent and liver specific manner. Biochem Biophys Res Commun 394(4):915-920

Ilowski M, Kleespies A, de Toni EN, Donabauer B, Jauch KW, Hengstler JG, Thasler WE (2011) Augmenter of liver regeneration (ALR) protects human hepatocytes against apoptosis. Biochem Biophys Res Commun 404(1):148-152

Kumar V, Gill KD (2009) Aluminium neurotoxicity: neurobehavioural and oxidative aspects. Arch Toxicol 83(11):965-978

Mielke H, Anger LT, Schug M, Hengstler JG, Stahlmann R, GundertRemy U (2011) A physiologically based toxicokinetic modelling approach to predict relevant concentrations for in vitro testing. Arch Toxicol 85(6):555-563

Nakayama S, Atsumi R, Takakusa H, Kobayashi Y, Kurihara A, Nagai Y, Nakai D, Okazaki O (2009) A zone classification system for risk assessment of idiosyncratic drug toxicity using daily dose and covalent binding. Drug Metab Dispos 37:1970-1977

Pestka JJ (2010) Deoxynivalenol: mechanisms of action, human exposure, and toxicological relevance. Arch Toxicol 84(9):663679

Rupp B, Appel KE, Gundert-Remy U (2010) Chronic oral LOAEL prediction by using a commercially available computational QSAR tool. Arch Toxicol 84(9):681-688

Schwarz M, Gocht T (2011) Towards the replacement of in vivo repeated dose systemic toxicity testing. Annual report 2011. SEURAT-1, vol 1, http://www.seurat-1.eu/pages/library/seurat1-annual-report.php (accessed Dec 8, 2011)

Tasaki M, Umemura T, Kijima A, Inoue T, Okamura T, Kuroiwa Y, Ishii Y, Nishikawa A (2009) Simultaneous induction of nonneoplastic and neoplastic lesions with highly proliferative hepatocytes following dietary exposure of rats to tocotrienol for 2 years. Arch Toxicol 83(11):1021-1030

Usui T, Mise M, Hashizume T, Yabuki M, Komuro S (2009) Evaluation of the potential for drug-induced liver injury based on in vitro covalent binding to human liver proteins. Drug Metab Dispos 37(12):2383-2892

Zhu G, Xiang X, Chen X, Wang L, Hu H, Weng S (2009) Renal dysfunction induced by long-term exposure to depleted uranium in rats. Arch Toxicol 83(1):37-46 